\title{
Research on Characteristics of Atmospheric Pollution and Meteorological Condition in South of Northern China
}

\author{
Jun Zhang, Xiaohui Song \\ Handan Meteorological Bureau, Handan, China \\ Email: zhangjun.sunny@163.com
}

How to cite this paper: Zhang, J. and Song, X.H. (2017) Research on Characteristics of Atmospheric Pollution and Meteorological Condition in South of Northern China. Journal of Geoscience and Environment Protection, 5, 73-84.

http://dx.doi.org/10.4236/gep.2017.51005

Received: December 5, 2016

Accepted: January 15, 2017

Published: January 18, 2017

Copyright $\odot 2017$ by authors and Scientific Research Publishing Inc. This work is licensed under the Creative Commons Attribution International License (CC BY 4.0).

http://creativecommons.org/licenses/by/4.0/

\begin{abstract}
Taking Handan City (the south of Northern China) as an example, and making use of the environmentally friendly materials of Handan Environmental Monitor Station in 2013-2014, the surface observational data of Handan Meteorological Station and the sounding data of Xingtai station, combined with the integrated analysis of numerical prediction and simulation, this paper shows that, in 2014, the air quality improved; the emission-reduction effect was significant; the days of heavy pollution decreased; and the days up to the standard increased; the annual average concentration of pollutants $\mathrm{PM}_{2.5}$ and $\mathrm{PM}_{10}$ in the whole city showed a decreasing tendency compared to the same period of last year. In 2014, there were a total of 9 weather processes of heavy pollution lasting more than 3 days and the duration was significantly shorter than that in 2013, which indicated that effective emission-reduction measures significantly shortened the duration of weather processes of heavy pollution. The comprehensive analysis of meteorological conditions, such as the days of light wind, wind speed, wind frequency, $\mathrm{PM}_{2.5}$ concentration at different wind directions, the thickness and intensity of the inversion layer, and the height of the mixed layer, showed that, compared with the same period in 2013, the general meteorological conditions of air pollutant dispersion were basically flat and slightly disadvantageous in 2014. Handan municipal government increased the intensity of the prevention and control of air pollution in 2014, promulgated and adopted a series of air pollution control policies and emission-reduction control measures, and achieved some results, especially the emission-reduction measures during the APEC meeting which were obviously effective.
\end{abstract}

\section{Keywords}

Heavy Pollution, Air Quality, Meteorological Conditions 


\section{Introduction}

In the 1960s and 1970s, the atmospheric environmental renovation in the world entered a comprehensive treatment stage. The concern as to the atmospheric environment should not only get involved with its source and changing process as well as the exploration of its relationship with meteorological conditions [1] [2] [3] [4]. With the accelerated process of industrialization, the cities in most developing countries all over the world are faced with serious air pollution problems. In recent years, air pollution in our country has become increasingly serious; the haze weather phenomena [5] [6] [7] [8] have increased, which threat seriously the social production and human health. The study on the features of atmospheric environment and its meteorological conditions has been the focus of many scholars [9]-[15]. The study shows that, under the premise of certain pollution sources, meteorological conditions are also an important factor affecting air pollution [16] [17] [18] [19] [20]. Wei Yuxiang [21] et al. point out that, through the study of the impact that different wind speeds have on air pollutants, the concentration of air pollutants is negatively correlated to wind velocity. When analyzing meteorological conditions of severe air pollution process in Central and Southern Hebei Province, in January 2013, Wang Congmei [22] et al. also point out that the wind field, inversion and other factors can cause the heavy pollution weather to increase. According to air pollution monitoring data from 2003 to 2008 in Chongqing, Zhou Guobing [23] et al. conclude that the polluted weather has obviously seasonal characteristics. Qi Donglin [24] et al. analyze the air quality and meteorological conditions from 2001 to 2011 in Xining, and the results show that the seasonal variation of air quality is obvious. Based on the study of air pollution characteristics in Lanzhou, Ma Minjin [25] et al. find that air pollution is closely related to the stable inversion layer.

Located in the south of Northern China and the eastern foot of Taihang Mountain, Handan's terrain decreases in a ladder-like form from west to east, whose western part is a mountainous area and eastern part is the North China Plain, belonging to a temperate continental monsoon climate zone. Since the reform and opening up, the industry in Handan has developed rapidly, the development model dominated by coal, iron and steel has caused massive emission of pollutants. In recent years, the persistent heavy pollution weather has become a meteorological disaster often appearing in the winter of Handan. Taking Handan for example and using the statistical method and numerical forecasting, this paper analyzes the meteorological conditions and its corresponding wind field, inversion layer and the height of mixed layer, etc., in the south of North China, which has a great significance to both the government policy and the improvement of the people's life quality.

\section{Materials and Methods}

\subsection{Sources of Data}

Using mass concentration of $\mathrm{PM}_{2.5}, \mathrm{PM}_{10}, \mathrm{O}_{3}, \mathrm{NO}_{2}, \mathrm{SO}_{2}, \mathrm{CO}$ and AQI material 
from 2013 to 2014 of Handan Environmental Monitoring Station, and the surface observational data of Handan Meteorological Station and the sounding data of Xingtai Station.

\subsection{Analysis Method}

Based on the statistical methods and the numerical forecast, analyze the influence factors of atmospheric environment and meteorological conditions in Handan and find the relevant meteorological conditions of air pollution.

\section{General Situation of Air Quality}

\subsection{Air Quality Grade Distribution in 2014}

According to the statistics of air quality monitoring data in environmental protection department in 2014, there were only two days with the weather of level 1 st air quality, accounting for $1 \%$; there were 86 days with the weather of level 2nd, accounting for 24\%; the weather of level 3rd mild pollution occupied the greatest ratio of $36 \%$, with 134 days; there were 52 days with middle level pollution, accounting for $14 \%$; there were 73 days with the weather of serious pollution, accounting for $20 \%$; the severe pollution weather accounted for $5 \%$, with 18 days (Figure 1).

\subsection{Standard and Severe Pollution Days in 2014}

Air quality index is less than or equal to 100 for the compliance date, greater than 100 is not up to date. In 2014, the number of days of the statistics reaching standard statistically (AQI $\leq 100)$ day by day in 4 monitoring points in downtown was 88 , and there were 91 days with the weather of severe pollution (AQI > 200) in the whole year.

\subsection{Main Pollutants in 2014}

In 2014, the primary pollutant in Handan was mainly $\mathrm{PM}_{2.5}$, appearing for 252

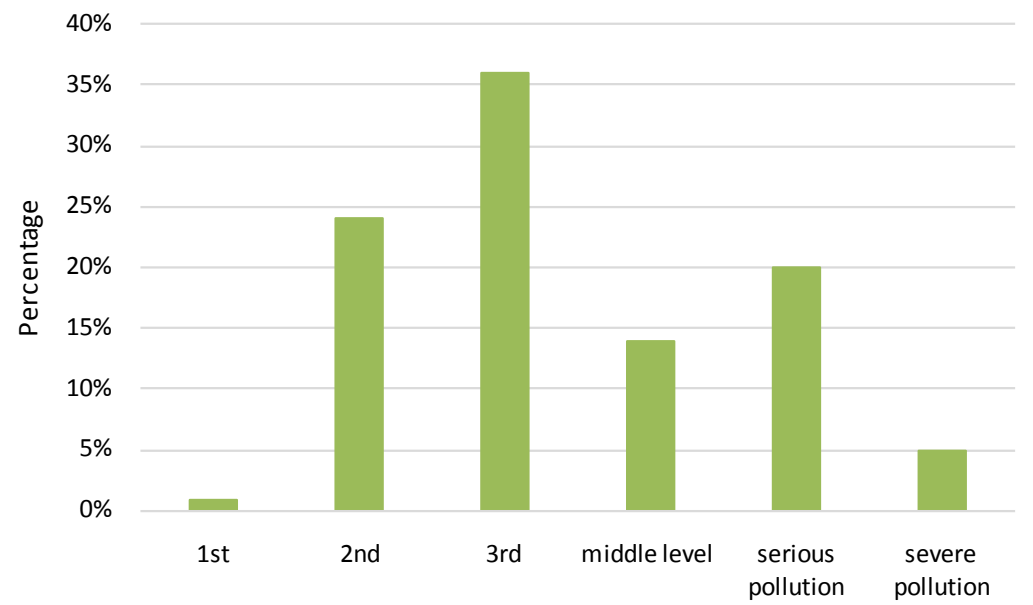

Figure 1. Distribution map of air quality in Handan city in 2014. 
days, which accounted for $69 \%$ of the whole year; followed by $\mathrm{PM}_{10}$, appearing for 80 days, which accounted for $22 \%$ of the whole year; there were 22 days with $\mathrm{O}_{3}$ primary pollutant, accounting for $6 \%$ of the whole year; $\mathrm{NO}_{2}$ accounted for $1 \%$; there was without the weather with $\mathrm{SO}_{2}$ and $\mathrm{CO}$ as primary pollutants was absent (Figure 2).

\section{Atmospheric Circulation Background and Monthly Variation Characteristics of Pollution in 2014}

\subsection{Atmospheric Circulation Background}

Flow field and field of pressure of large scale are directly influenced by atmospheric circulation background, and accumulation and spread of pollutants are further influenced greatly. In the season of unapparent zonal circulation, the north-south exchange of airflow is obvious, and it is conducive to the spread of pollutants with the weather such as the wind of cold air; in the season of obvious zonal circulation, the probability of appearance of fog and haze is always increased, pollutants are easy to be accumulated, and consequently, the severe pollution is formed. In 2014, the northern hemisphere polar vortex presented the north-south structure, and polar vortex showed as southward deflection and strong. Southern part of northern China was located at the bottom of the vortex, and it was controlled by northwest airflow. It was beneficial to cold air keeping down south and to influence North China, however, because cold air activity was weak and there was limited influence on Handan, it was very easy to form the phased fog and haze weather. In 2014, the severe pollution in southern part of northern China mainly happened in autumn and winter as well as early spring, and namely, October to December and January to March. Among which, there was the maximum days of the weather with serious pollution in January, followed by February and October. Starting from April, with the rise of temperature and the strengthening of turbulent motion, the weather with severe

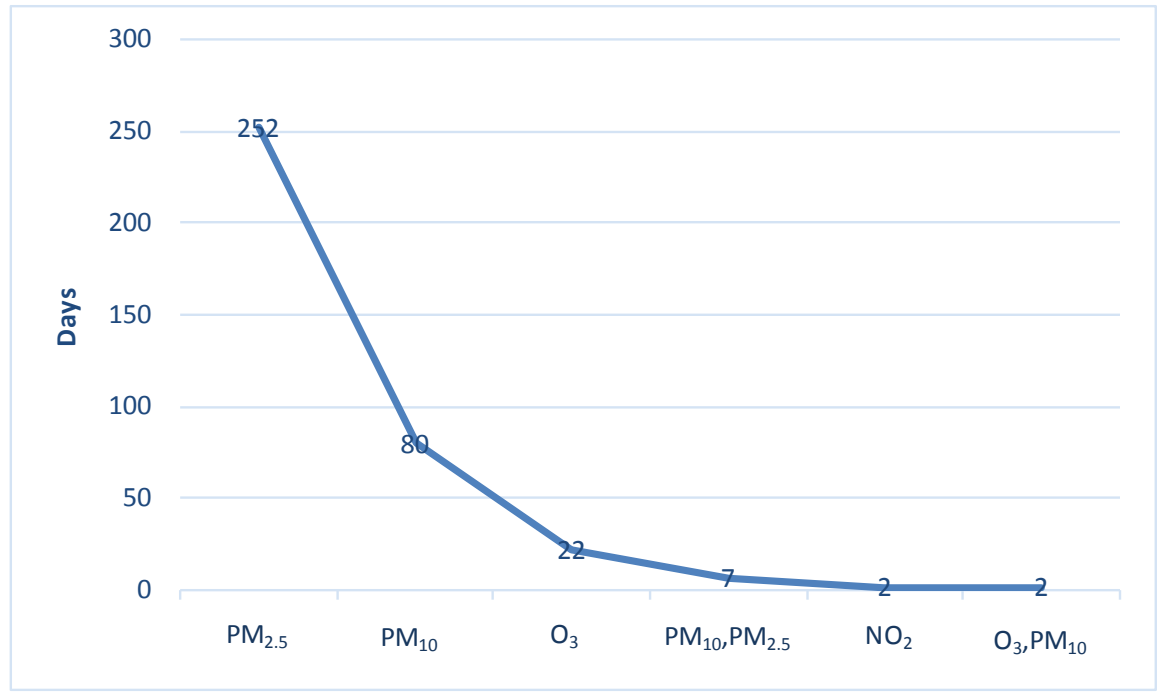

Figure 2. Days of major pollutants in 2014 . 
pollution has been decreased significantly.

\subsection{Monthly Variation of Heavy Pollution Days and Concentrations of Pollutants in Handan City}

\subsubsection{Analysis on the Characteristics of the Main Pollutants}

The change trend of $\mathrm{PM}_{2.5}$ and $\mathrm{PM}_{10}$ is roughly consistent with the monthly change characteristic of AQI $>200$, and the value of autumn and winter as well as early spring is relatively high. From January to April, the mean concentration of $\mathrm{PM}_{2.5}$ and $\mathrm{PM}_{10}$ stayed at high level and presented the downtrend; between May and September, the trend was slow; in October, the average density value started to rise, while from October to December, it kept at a high value. Through analysis on the characteristics of pollutant $\mathrm{O}_{3}$, it is discovered that the change trend of $\mathrm{O}_{3}$ is totally different from that of $\mathrm{PM}_{2.5}$ and $\mathrm{PM}_{10}$, and $\mathrm{PM}_{2.5}$ and $\mathrm{PM}_{10}$ are decreased with the rise of temperature, while the change of $\mathrm{O}_{3}$ is increased with the rise of temperature and the increase of average density. From January to May, the change of $\mathrm{O}_{3}$ presented a rise tendency, and it reached the maximum value of the whole year in May (this kind of situation may be connected with the situation of many days of high temperature weather in the corresponding period). From June to August, $\mathrm{O}_{3}$ still kept at the status of high value, and starting from September, $\mathrm{O}_{3}$ presented the rapid downtrend with the reduction of temperature.

\subsubsection{The Process of Persistent Severe Pollution}

In 2014, there was a total of 9 severe pollution weather processes for 3 consecutive days or above, and among which, the longest was continued for 15 days, while in 2013, the longest severe pollution weather was continued for 29 days. It shows that the duration of severe pollution weather is shortened obviously with the effective emission reduction measures in Handan.

\section{Contrastive Analysis on Air Pollution Meteorological Conditions between 2014 and 2013}

\subsection{Analysis on the Number of Days of Small Wind}

For gaseous pollutants and particulate pollutants, the wind mainly shows the ability of advecting, but it is one of the meteorological factors with the strongest local characteristic. According to the comparison of the number of days of the daily mean small wind (the daily mean wind speed $<1.5 \mathrm{~m} / \mathrm{s}$ ) in Handan between 2014 and 2013, it is discovered that in 2014, the number of the daily mean small wind days was greater than that of 2013 (Figure 3). The smaller wind speed is adverse to the spread of water vapour and pollutants, and it is also the advantage for the development and constant pollution of fog and haze weather. Therefore, the number of small wind days in 2014 shows that the meteorological condition is adverse to the spread of atmospheric pollutants.

\subsection{Analysis on Wind Speed}

The concentration of pollutants discharged in atmosphere is inversely 


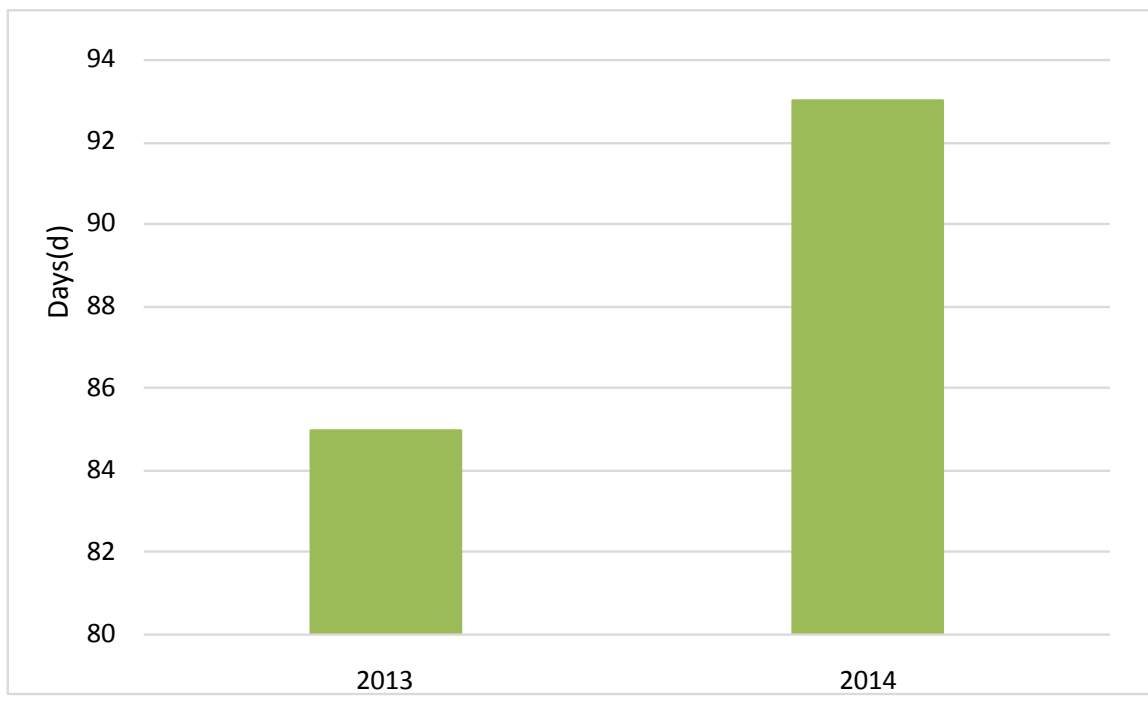

Figure 3. 2014 and 2013 in Handan City, the average number of days the wind (wind speed $<1.5 \mathrm{~m} / \mathrm{s})$.

proportional to the average wind velocity, because the increase of wind power makes the turbulent diffusion enhanced, which plays the role of diluting pollution. According to the statistics of the wind speed and wind direction in Handan severe pollution season (January to March and October to December) of 2014 and 2013 (Figure 4), it can be seen that the average wind velocity on each wind direction in 2014 was decreased overall comparing to that of 2013. The average wind velocity of the south wind is the maximum, with $2.56 \mathrm{~m} / \mathrm{s}$, which is a little less than $2.7 \mathrm{~m} / \mathrm{s}$ in 2013 . The average wind velocity of severe pollution season in 2014 shows that the meteorological condition is adverse to the spread of atmospheric pollutants.

\subsection{Analysis on Wind Frequency}

According to the statistics of wind direction frequency of severe pollution season (January to March and October to December) in 2014 and 2013 (Figure 5), the results show that the wind direction frequency in 2014 is roughly consistent with that in 2013, giving priority to north wind (N) and south wind (S), and both of them account for around 20\%; the wind of west-south-west (WSW) is the minimum, and it respectively accounts for $0.51 \%$ and $0.41 \%$ in the corresponding 2014 and 2013.

\subsection{Analysis on $\mathrm{PM}_{2.5}$ Mean Concentration under Each Wind Direction}

Through statistics of $\mathrm{PM}_{2.5}$ mean concentration under each wind direction in Handan severe pollution season in 2014 and 2013 (Figure 6), it is summarized that under the north wind $(\mathrm{N})$, the concentration of $\mathrm{PM}_{2.5}$ is the highest in both 2014 and 2013 , with it respectively being $180.8 \mu \mathrm{g} / \mathrm{m}^{3}$ and $231.5 \mu \mathrm{g} / \mathrm{m}^{3}$; when there is the wind of west-north-west (WNW), the concentration of $\mathrm{PM}_{2.5}$ is the minimum, with it respectively being $74.4 \mu \mathrm{g} / \mathrm{m}^{3}$ and $106.6 \mu \mathrm{g} / \mathrm{m}^{3}$. It can be seen 


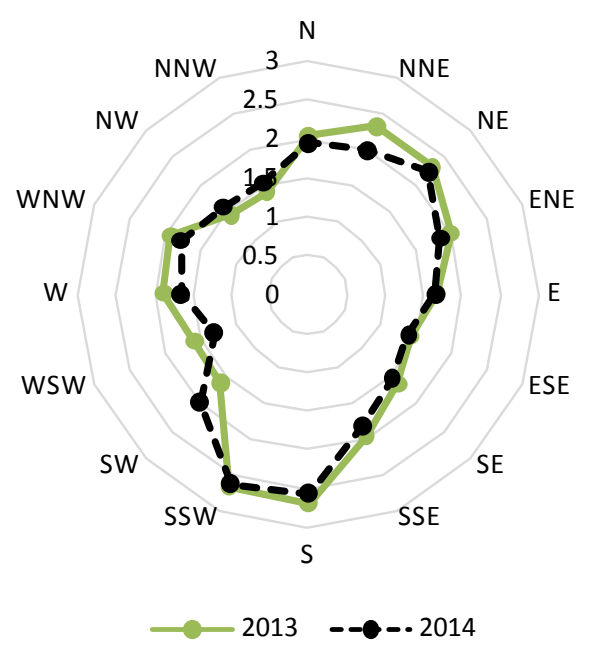

Figure 4. 2014 and 2013 Handan heavy pollution season wind rose diagram.

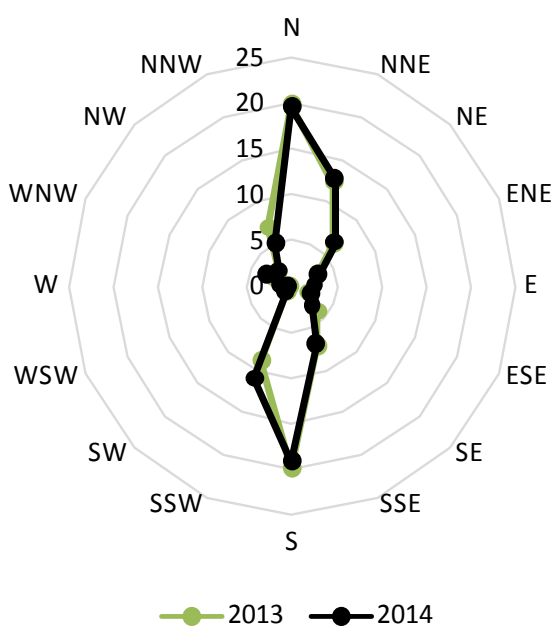

Figure 5. 2014 and 2013, Handan City, heavy pollution monsoon rose diagram.

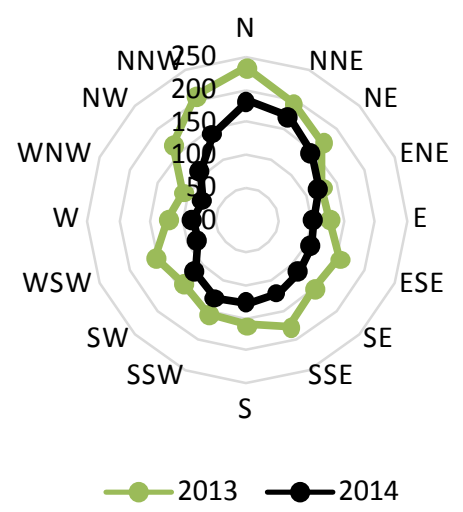

Figure 6. 2014 and 2013 Handan heavy pollution season wind down $\mathrm{PM}_{2.5}$ concentration rose. 
that the concentration of $\mathrm{PM}_{2.5}$ in 2014 in each direction is reduced comparing to that in 2013.

\subsection{Analysis on Temperature Inversion}

Under the background of stable general atmospheric circulation, the existence of low-level inversion layer hinders the atmospheric vertical movement, and it is adverse to the spread of atmospheric pollutants. The increase of inversion layer thickness and the rise of inversion intensity are beneficial to the accumulation of pollutants. According to the statistics of the temperature inversion data of Xingtai sounding station, the inversion layer thickness of 2014 is smaller than that of 2013 overall, and especially in January, the average thickness in 2014 was $255 \mathrm{~m}$, while the average thickness in 2013 was $352 \mathrm{~m}$; in January 2014, there were 15 days with the weather of persistent severe pollution, without extraordinary days, while in January 2013, the number of days with the weather of persistent severe pollution reached up to 29 , with the daily mean value of AQI being 500 and the extraordinary days being 5; analysis from the intension of temperature inversion, in 2014, it is generally stronger than that of 2013, and especially the intension of temperature inversion in autumn and winter is much stronger that of the corresponding period in the past year. In a word, from the perspective of inversion layer thickness, the meteorological condition in 2014 is favorable than that of 2013; from the perspective of the intension of temperature inversion, the meteorological condition in 2014 is unfavorable than that of 2013 (Figure 7).

\subsection{Analysis on Mixing Layer Height}

The lower mixing layer height is adverse to the spread of pollutants, and with the small ground wind speed and air pollutants being deposited on the being deposited on the surface layer, the weather of severe pollution is caused. According to the statistics of mixing layer height on Xingtai sounding station (Figure 8), the results show that mixing layer height between January and April 2014 and between August and November 2014 is obviously lower than the same months in 2013; apparently, Handan mixing layer height is adverse to the spread of pollutants comparing with that in 2013.

\section{Contrastive Analysis on Air Pollution Status in 2014 and 2013}

According to the statistics of air quality monitoring data in 2014 and 2013, the concentration of pollutants $\mathrm{PM}_{2.5}$ and $\mathrm{PM}_{10}$ in the whole city in 2014 presents the downtrend comparing to the corresponding period in the past year, and $\mathrm{PM}_{2.5}$ reduced $17 \%$, while $\mathrm{PM}_{10}$ reduced $21 \%$. According to the contrastive analysis of standard reaching days and severe pollution days, Handan air quality in 2014 is obviously improved comparing with that in 2013, with a significant effect of emission reduction. 34 days of researching standard in 2014 were increased comparing with that of 2013, and 18 days of severe pollution were reduced. 

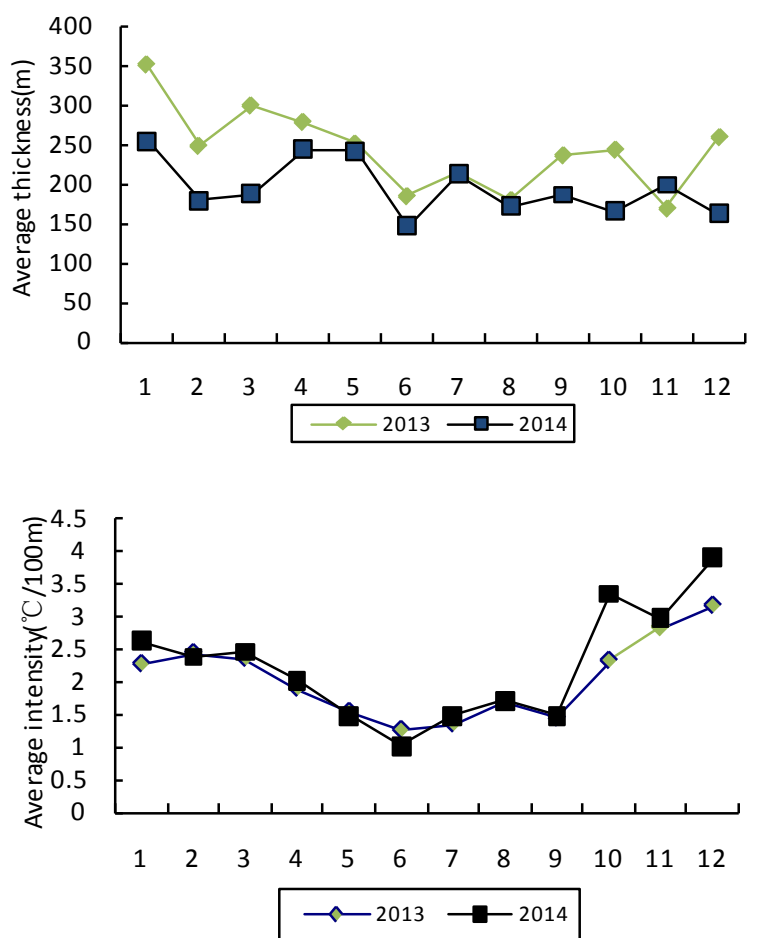

Figure 7. In 2014 and 2013 Xingtai inversion layer change average thickness and strength of the month.

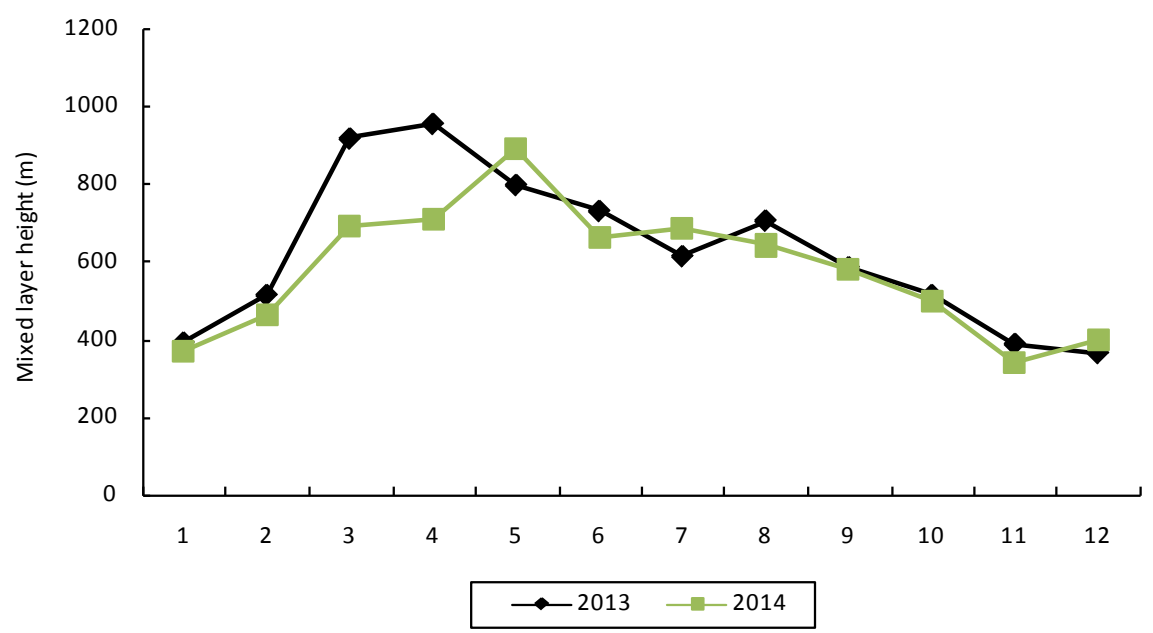

Figure 8. Monthly variation of mixed layer height between 2014 and 2013.

\section{Analysis on Air Quality and Meteorological Condition during APEC Meeting in 2014}

In order to guarantee the good air quality during APEC meeting, as a city around Beijing, Handan's local government increased the emission reduction and adjustment strength, and the government implemented the measures such as traffic control for motor vehicles and the measures including production suspending and production restriction particularly for some enterprises, which made the concentration of pollutants reduced obviously. After ending the meeting, the air quality was decreased slightly, which shows that it is related to the 
cancel of emission reduction measures. Before (7 October to 31 October, 2014) and after (11 November to 30 November, 2014) APEC meeting, the mean concentration of $\mathrm{PM}_{2.5}$ was $136 \mu \mathrm{g} / \mathrm{m}^{3}$, while during APEC meeting, the concentration of $\mathrm{PM}_{2.5}$ was $87 \mu \mathrm{g} / \mathrm{m}^{3}$, but $36 \% \mathrm{PM}_{2.5}$ concentration was reduced during the period of emission reduction and adjustment. It shows that there is obvious emission reduction and adjustment effect on controlling the concentration of pollutants. In addition, the meteorological condition in the period of 23 October to 26 October was the same comparing with that in the period of 7 November and 10 November, but the mean concentration of $\mathrm{PM}_{2.5}$ in 23 October and 26 October was $135 \mu \mathrm{g} / \mathrm{m}^{3}$, with the peak concentration reaching $494 \mu \mathrm{g} / \mathrm{m}^{3}$. However, the mean concentration of $\mathrm{PM}_{2.5}$ from 7 November to 10 November was only $87 \mu \mathrm{g} / \mathrm{m}^{3}$, with the peak concentration being $260 \mu \mathrm{g} / \mathrm{m}^{3}$. It shows that the concentration of $\mathrm{PM}_{2.5}$ and peak concentration are reduced with the effective emission reduction measures, and the emergence of severe pollution is effectively avoided. In APEC meeting, from the perspective of the spread of atmospheric pollutants, there was good meteorological condition of the spread of atmospheric pollutants was good during the meeting, but the meteorological condition in later period was bad, and without strong cold air southward, it is easy to have the meteorological condition which is adverse to the spread of pollutants is easy to appear. In 9 November, 2014, Handan air pollution meteorological condition reached level 6; there was no significant accumulation and the atmospheric air quality was improved because the discharge of atmospheric pollutants was greatly reduced and the effective joint defense and joint control measures were adopted, and the actual air quality at that day was level 4 . The air pollution meteorological condition level is obviously higher than air quality actual situation level, and there is no persistent severe pollution. The effective emission reduction measure makes the pollution reduce 2 levels, and the emergence of severe pollution is avoided.

\section{Conclusion}

Comprehensive analysis of meteorological conditions shows that comparing with the corresponding period in 2013, the overall meteorological condition of the spread of atmospheric pollutants in 2014 held the line basically, and it was slightly unfavorable; the air quality was improved slightly, and the annual mean concentration of pollutants $\mathrm{PM}_{2.5}$ and $\mathrm{PM}_{10}$ showed downtrend comparing with the corresponding period in last year. It manifests that a certain effect has been achieved with a series of atmospheric pollution prevention, emission reduction and regulation and control countermeasures, especially the emission reduction countermeasures during APEC meeting, and moreover, a very obvious effect was achieved.

\section{References}

[1] Ma, J.Z., Wang, W., Chen, Y., et al. (2012) The IPAC-NC Field Campaign: A Pollution and Oxidization Pool in the Lower Atmosphere over Huabei. China Atmos- 
pheric Chemistry and Physics, 12, 3883-3908. https://doi.org/10.5194/acp-12-3883-2012

[2] Wu, Q.M. and Zhang, S.J. (2010) The Pollution Influencing Cause Analysis of a Fog-Haze Process. Meteorological and Environmental Sciences, 33, 12-16.

[3] Ma, J.Z., Chen, Y., Wang, W., et al. (2010) Strong Air Pollution Causes Widespread Haze-Clouds over China. Journal of Geophysical Research-Atmospheres, 115, D18204. https://doi.org/10.1029/2009jd013065

[4] Zhang, J.Z., Sun, J., Wang, G.L., et al. (2014) Relation between the Spatial Temporal Distribution Characteristics of Air Quality Index and Meteorological Conditions in Beijing. Meteorological and Environmental Sciences, 37, 33-39.

[5] Wang, Z.F., Li, J., Wang, Z., et al. (2014) Modeling Study of Regional Severe Hazes over Mid-Eastern China in January 2013 and Its Implications on Pollution Prevention and Control. Science China (Earth Science), 57, 3-13. https://doi.org/10.1007/s11430-013-4793-0

[6] Guan, Y. and He, L.F. (2013) Analysis of the January 2013 Atmosphere Circulation and Weather. Meteorological Monthly, 39, 531-536.

[7] Tiwari, S. and Chate, D.M. (2012) Variations in Mass of PM10, PM2.5 and PM1 during the Monsoon and the Winter at New Delhi. Aerosol and Air Quality Research, 12, 20-29. https://doi.org/10.4209/aaqr.2011.06.0075

[8] Elangasinghe, M.A., Singhal, N., Dirks, K.N., et al. (2014) Complex Time Series Analysis of PM10 and PM2.5 for a Coastal Site Using Artificial Neural Network Modeling and k-Means Clustering. Atmospheric Environment, 94, 106-116. https://doi.org/10.1016/j.atmosenv.2014.04.051

[9] Wu, E.F. (2006) The Transformation Relation between Ozone and Nitrogen-Oxide in Ambient Air over Summer. Environmental Science \& Technology, 29, 56-58.

[10] Guo, Y., Barnett, A.G., Zhang, Y., et al. (2010) The Short-Term Effect of Air Pollution on Cardiovascular Mortality in Tianjin, China: Comparison of Time Series and Case-Cross over Analyses. Science of the Total Environment, 409, 300-306. https://doi.org/10.1016/j.scitotenv.2010.10.013

[11] Shi, Y.Z., Xu, Y.F., Wang, G.C., et al. (2009) Study of the Weekend Effect of $\mathrm{O}_{3}, \mathrm{NO}_{\mathrm{x}}$ and Other Pollutants in Summer of Beijing. Environmental Science, 30, 2832-2838. (In Chinese)

[12] Zhang, Z., Tang, J. and Tang, J. (2007) Weekend Effect of Urban Air Pollution Index and Meteorological Elements: The Case of Wuxi. Journal of Nanjing University, 43, 643-654. (In Chinese)

[13] Fan, S.J., Wang, B.M., Tesche, M., et al. (2008) Meteorological Conditions and Structures of Atmospheric Boundary Layer in October 2004 over Pearl River Delta Area. Atmospheric Environment, 42, 6174-6186. https://doi.org/10.1016/j.atmosenv.2008.01.067

[14] Wu, D., Liu, Q., Liang, Y., et al. (2012) Hazy Weather Formation and Visibility Deterioration Resulted from Fine Particulate (PM2.5) Pollutions in Guangdong and Hong Kong. Acta Scientiae Circumstantiae, 32, 2660-2669.

[15] Zhang, L.P., Yang, Z.Y. and Chen, Z. (2000) Canonical Correlation Coefficients and Their Applications in a Short Range Climate Prediction. Chinese Journal of Atmospheric Science, 24, 427-432.

[16] Fan, S.J., Wang, A.Y., Fan, Q., et al. (2006) Atmospheric Boundary Layer Features of Pearl River Delta and Its Conception Model. China Environmental Science, 26, 4-6.

[17] Shao, L.Y., Li, J.J., Zhao, H.Y., et al. (2007) Associations between Particle Physico- 
Chemical Characteristics and Oxidative Capacity: An Indoor PM10 Study in Beijing, China. Atmospheric Environment, 41, 5316-5326. https://doi.org/10.1016/j.atmosenv.2007.02.038

[18] Wang, G.L., Xue, J.J. and Zhang, J.J. (2016) Analysis of Spatial-Temporal Distribution Characteristics and Main Cause of Air Pollution in Beijing-Tianjin-Hebei Region in 2014. Meteorological and Environmental Sciences, 39, 34-42.

[19] Gao, H. and Chen, J. (2014) Regional Distributions of Air Pollution Index in Major Cities of China. Periodical of Ocean University of China: Natural Science Edition, No. 10, 25-34.

[20] Gao, Q., Liu, J., Li, W., et al. (2015) Comparative Analysis and Inspiration of Air Quality Index (AQI) between China and America. Environmental Science, 36, 1141-1147.

[21] Wei, Y., Dong, X., Yin, Y., et al. (2009) Variation Characteristics of $\mathrm{SO}_{2}, \mathrm{NO}_{2}$ and PM (10) and Their Relationship with Meteorological Conditions in Nanjing. Journal of Atmospheric Sciences, 32, 451-457.

[22] Wang, C., Yang, Y., Li, Y., el al. (2013) Analysis on Meteorological Conditions and Causes of Serious Pollution in Central and Southern Hebei Province in January 2013. Environmental Science Research, 26, 695-702.

[23] Zhou, G. and Wang, S. (2010) Study on Air Pollution Weather Characteristics in the Urban Area of Chongqing City. The Resources and Environment of the Yangtze River Basin, 19, 1345-1349.

[24] Qi, D., Zhang, J., Li, X., et al. (2014) Characteristics of Air Quality in Xining City from 2001 to 2011 and Its Relationship with Meteorological Conditions. Journal of Meteorology and Environment, 30, 51-59.

[25] Ma, M., Guo, S., Wang, S., et al. (2012) Analysis of the Characteristics of Air Pollution in Lanzhou in Recent 11 Years and Its Influence on Boundary Layer Structure. Journal of Lanzhou University (Natural Science Edition), 48, 69-73.

\section{Submit or recommend next manuscript to SCIRP and we will provide best service for you:}

Accepting pre-submission inquiries through Email, Facebook, LinkedIn, Twitter, etc. A wide selection of journals (inclusive of 9 subjects, more than 200 journals) Providing 24-hour high-quality service User-friendly online submission system Fair and swift peer-review system Efficient typesetting and proofreading procedure Display of the result of downloads and visits, as well as the number of cited articles Maximum dissemination of your research work

Submit your manuscript at: http://papersubmission.scirp.org/ Or contact gep@scirp.org 